\title{
A talent training mode based on school-enterprise cooperation and different directions of autonomous enrollment students of higher vocational school
}

\author{
Jiao Feng ${ }^{1, a}$, Shuang Gao, b and Yan Zhu ${ }^{1, c}$ \\ ${ }^{1}$ Biological Engineering Department, Liaoning Economic Management Cadre Institute, Shenyang, \\ 110122, P. R. China; \\ afengjiao720@163.com, bIngaos@126.com, c46581081@qq.com
}

\begin{abstract}
Keywords: school-enterprise cooperation, autonomous enrollment, different directions, higher vocational education

Abstract. Relying on industries and enterprises, the talent training mode serves the regional economy. In this study, a talent training mode which is based on the school-enterprise cooperation and educations of different levels and different directions was carried out on the students of autonomous enrollment. The talent training mode of school-enterprise cooperation could satisfy the needs of regional economic construction and social development, while that of different levels and directions could satisfy the diversity of social needs. The perfect combination of the two kinds of talent training mode could actively promote the construction of modern vocational education system in our province and thus satisfy the diversification of higher vocational education.
\end{abstract}

\section{Introduction}

The autonomous enrollment of higher vocational colleges is a professional reform of the enrollment system of higher education in our country. It is also the new normal development of high vocational education in our country. Higher vocational colleges could take a variety of assessment methods to recruit different types of students, while the candidate could choose the major and its related technical field with their own interests. The autonomous enrollment could realize the unique feature of dual adaptation of high vocational education and students. The career potential of students was furthest developed and the talents that were suitable for social and economic development and cultivation characteristics of higher vocational school were chosen by autonomous enrollment. However, there are many problems in teaching and employment patterns of autonomous enrollment students, because their training model is inconformity with their learning characteristics. The talent training mode reform of autonomous enrollment students, the realization of the talent training goal of autonomous enrollment, and how to carry out the education idea of "taking students as the foundation" are the three problems of higher vocational colleges to be solved urgently.

\section{The present training situation of autonomous enrollment students}

The autonomous enrollment policy is more emphasis on the two-way choices between candidates' ambitions, expertise and major choice and the future direction of employment [1]. Its purpose is to better realize the reasonable allocation between students and educational resources. However, compared with the unified enrollment students, autonomous enrollment students have following characteristics: with poor theoretical knowledge, without the strength to participate in the unified examination and with good practice ability and misfit in the training mode of higher vocational education [2,3]. In the present, the training mode of autonomous enrollment students in higher vocational colleges has not completely broken the shackles of traditional education. It is in an awkward position of mismatch between teaching mode and students' abilities, students' interests and major and students' vocational abilities and the requirements of enterprise. 


\subsection{The implementation of the training mode of higher vocational college independent enrollment students based on school-enterprise cooperation and the different directions}

Because of the popularization and diversification of higher vocational education, it should have different quality standards for different vocational schools and also the students from the same school and the same major. The talent training mode of autonomous enrollment students of higher vocational schools should be reformed with different levels and directions under the background of the popularization of higher vocational education. Students would strengthen the core abilities in the practice base outside and inside the campus by the constructions of enterprise experts and professional teachers $[4,5]$.

Taking food biotechnology as an example, the training mode was divided into four stages.

2.1.1 The training stage of moral character and vocational ability (the first year in college). In this stage, students could understand the requirements of enterprise position. They could master the basic theoretical knowledge and practical skills in their major and partially understand enterprise connotation and the possible development directions in the future. In particular, with the integration of theory and practice of basic chemistry, students could master a variety of practical skills of production and detection. They participated in professional associations and experience the mode of enterprise culture into the campus. Moreover, with the strict quality education, the students could form good study habits and lifestyle and promote the comprehensive quality as soon as possible. Combined with the education of vocational ability, students could confront their own characteristics, learning abilities and practical abilities and understand the enterprise position at the end of the first stage. Furthermore, they could accept highly individualized orientation of professional and vocational directions from their professional teachers.

2.1.2 The job rotation stage of different levels and different directions (the second year in the collage). In this stage, students practiced with project-driven job rotation in the corresponding training room. According to the talent training scheme, school and enterprise formulated job rotation programs together. Technical staff from the enterprise and professional teachers shared the integration courses of theory and practice of rotation module and calculated students' practical skills by simulating the real production, determination and marketing position. At the job rotation stage, the students have accumulated experience, improved the ability of solving practical problems in the work and correctly assess their professionalism.

After the short rotation in three directions, students chose the specific core major direction according to examination results, their own personality characteristics and the main intention and the assessment of school and enterprise experts. By using project teaching, the targeted instruction and the enterprise practice training were carried out in order to strengthen professional core abilities of students. The teaching effects of the core curriculum determined the training level of students. With the overall assessment of school and enterprise experts and the independent choice, students determined the direction of professional learning [6,7]. Consequently, the acceptance ability, learning ability, logical thinking and self innovation of students who studied in the same direction were close to each other. Both the teaching progress and the depth and breadth of knowledge were more strength in the specific direction of learning process than those of job rotation progress. In addition, the shackles of taking care of the majority in the original teaching method were avoided and an operational platform was provided for students to play personal strengths.

2.1.3 The practice stage of the main professional direction (the third year in the collage). In this stage, students chose the suitable enterprise for the post practice and on-the-job training. With the learning and practice in the first two stages, the professional qualities, technical levels and service abilities of students could satisfy the requirements of the position. Furthermore, the running-in period between students and enterprise was shorten. Enterprise was not only the participants, but also the beneficiaries [8,9]. The outstanding talents with comprehensive abilities could be selected pertinently. The seamless connection between students' professional abilities and the requirements of enterprise was realized. 
2.1.4 The continuing education stage on the basis of the concept of lifelong education for students (after graduation). Because of bottlenecks of job rotation and promotion, some graduates of higher vocational school and enterprise employees wanted to obtain higher vocational qualifications or undergraduate degree. Relying on the professional skill appraisal organization, a vocational ability training and appraisal team was established and the vocational qualification training and identification (such as senior winemaker professional qualification and senior food inspection professional qualification) were carried out to trainee. This training mode could improve the quality of vocational education and vocational qualification training. It could actively cultivate innovative talents that seamlessly connected with industry and enterprises.

\subsection{The superiority and promotion of the training mode of higher vocational college independent enrollment students based on school-enterprise cooperation and the different directions}

2.2.1 The curriculum system was constructed by both school and enterprise. Curriculum took the development of students' comprehensive vocational abilities as the prime task and highlighted the main position of the practice. Combined with the specific situation of the enterprise, the curriculum system was constructed based on the typical tasks and thus fully reflected the professionalism, practicality and openness. Moreover, in order to strengthen the practical ability of students, the application of enterprise technology was introduced into the teaching process and the professional course is divided into several task modules corresponding to the enterprise work flow.

2.2.2 Combined with major and post, the teaching plan of multi - level and different directions was developed. According to the talent demand of the enterprise post, the personnel training plan was discussed and formulated by higher vocational college and enterprises together on the basis of professional training goal and career development of students. It solved the skills demand of enterprise position and enabled students to have a good professional background and development space.

2.2.3 Combined with major, vocation and post, the student assessment was improved. In the process of the training with different levels and different directions, students should past the comprehensive assessment of professional knowledge, skills and basic professional qualities so that they could have good professional foundation and development potential. Furthermore, according to the requirements of the enterprise, the students must get the professional qualification certificate issued by the national vocational skills appraisal center to obtain professional qualifications. In the process of post practice, the knowledge and skills of practice position and professional quality of students were comprehensively examined by means of centralized assessment.

2.2.4 The Teaching management and assessment was carried out by the teacher team that constructed by school and enterprise. In the process of implementation curriculum, the "mobile classroom" was created. Enterprises focused on teaching and the evaluation of students while professional teachers of school focused on management of students. The professional teachers tracked the whole processes of the practice of students in enterprises and understood exactly the post requirements of enterprises in turn and thus to improve their professional abilities. In the talent training mode based on school-enterprise cooperation and different directions of autonomous enrollment students, it is necessary for teachers to go deep into the enterprise, and discuss the types of posts, post knowledge and post abilities. In addition, in order to explore ideas and innovative teaching methods, teachers should apply the new concept of higher vocational education to the reform of talent training mode. They could enhance the teaching ability and also benefit in the field of career.

2.2.5 Take ability as the main line, the potential of autonomous enrollment students was fully developed. Take the student as the center, take the ability as the standard, the talent training mode based on school-enterprise cooperation and different directions of autonomous enrollment students was constructed. It satisfied the development of the personality of students and gave them the opportunity to choose independently. Moreover, It emphasized on the integration of theory and practice and the integration of basic theory and professional skill, stimulated learning desire of students, developed their learning potential and promoted their professional quality. 
2.2.6 The professional abilities of students were improved. With the training mode of school-enterprise cooperation and different levels and different directions, the authentic and effective learning and practice places were offered to independent enrollment students. Moreover, the distance between the demand of modern enterprise and the teaching of higher vocational school was narrowed furthest. It played an important role in improving students' professional quality. In addition, the psychological preparation of entry, the adaptability of enterprise culture and enterprise management system of students were involved earlier. The abilities of students to adapt to the post were significantly enhanced. The students experienced the quality consciousness, cost consciousness and team consciousness that needed by the enterprise and fully satisfied the requirements of the post, enhanced the job competitiveness and worked directly after graduation.

In this talent training mode, the vocational abilities to fit professional needs of students were developed by both the school and the enterprise. Students practiced on the different positions of enterprise while their abilities and learning results were assessed and identified by both enterprise and school. Furthermore, the project teaching level and employment qualities and post competencies of students were improved.

\section{Conclusion}

The talent training mode which is based on the school-enterprise cooperation and educations of different levels and different directions for autonomous enrollment students can train professional and technical talents with seamless connection with enterprises and thus serve Liaoning local economy. It satisfied the diversified demand of higher vocational education and solved the contradiction between the relatively poor theoretical foundation, the poor self-discipline and the outstanding practical ability in the process of training the professional abilities of autonomous enrollment students. This talent training mode could promote the construction of modern vocational education system. It is expected to promote the quality and increase the efficiency of Liaoning economic.

\section{Acknowledgment}

This work was supported by Liaoning education planning project (JG16EB121, JG16EB122 and JG16EB130).

\section{References}

[1] J. Cao: Journal of Lanzhou Institute of Education. Vol. 29 (2013), p. 59.

[2] Z. Mao, L. Liu: Scientific \& Technical Information of Gansu, Vol. 44 (2015), p. 62.

[3] J. Wang: Journal of Wuhu Vocational Institute of Technology, Vol. 15 (2013), p. 11.

[4] F. Huang, Y. Shen: Higher Education Forum, Vol. 5 (2010), p. 107.

[5] Y. Hu, Y. Zhu, M. Xiang: Education for Chinese After-school (Theory), Vol. 5 (2016), p. 13.

[6] Y. Li, F. Liao: Vocational and Technical Education, Vol. 36 (2015), p. 44.

[7] C. Wang, J. Xu: Journal of Harbin Vocational \& Technical College, Vol. 2 (2016), p. 1.

[8] J. Ding: China Higher Education Research, Vol. 6 (2011), p. 76.

[9] S. Wang, W. Lv, Y. Liu: Modern Education Management, Vol. 2 (2015), p. 57. 